\title{
The application of the percentage change calculation in the context of inflation in Mathematical Literacy
}

\section{Author:}

Sarah Bansilal ${ }^{1}$ (D)

Affiliation:

${ }^{1}$ School of Education,

University of KwaZulu-Natal,

South Africa

Corresponding author:

Sarah Bansilal,

Bansilals@ukzn.ac.za

Dates:

Received: 21 Sept. 2016

Accepted: 01 May 2017

Published: 31 July 2017

How to cite this article: Bansilal, S. (2017). The application of the percentage change calculation in the context of inflation in Mathematical Literacy. Pythagoras, 38(1), a314. https://doi.org/10.4102/ pythagoras.v38i1.314

\section{Copyright:}

(C) 2017. The Authors.

Licensee: AOSIS. This work is licensed under the

Creative Commons

Attribution License.
Read online:
The school subject Mathematical Literacy requires application of mathematics procedures in various contextual settings, but not much is known about the ways in which students engage with contextual settings such as inflation. This qualitative study was conducted with in-service Mathematical Literacy teachers in South Africa with the purpose of exploring the extent to which the teachers recognised the contextual constraints involved in applying the percentage change calculation to the inflation context. The written responses of the 406 Mathematical Literacy teachers were scrutinised to identify their interpretations of the contextual constraints involved in applying the percentage change procedure to the context of inflation. The item required the application of two successive percentage change operations (corresponding to the inflation rates for the 2 years). Of the 406 responses that were analysed, 260 (65\%) were unable to take account of all the contextual constraints. There were 108 teachers who reduced the procedure to a one-step calculation while 64 teachers interpreted the context as a percentage decrease scenario. A large number of teachers (162) struggled with the interpretation of the role of the year, $k$, in the relationship between the quantities. The findings indicate that engagement with and understanding of the concept of inflation is dependent on a synthesis of the contextual constraints into the mathematical procedures. This article provides some insights into the struggles with making sense of the contextual nature of inflation which is an area that has received little attention in mathematics education studies. The teachers' struggles likely mirror learners' struggles and hence the research applies in a similar way to learners.

\section{Introduction}

Globally there has been much interest in how learners at school could be better prepared to participate meaningfully in situations they encounter out of school. This out-of-school world has increasingly become influenced by mathematics, and is described by Orrill (2001, p. xiv) as being 'awash with numbers' and drenched with data. The increasing emphasis on the application of mathematics in 'realistic' settings is reflected in calls for curricula to focus on applications of mathematics to real-world situations rather than mathematics in isolation (Cooper \& Dunne, 2004; De Lange 2003; Department of Basic Education [DBE], 2011a; Moschkovich, 2002; Organisation for Economic Co-operation and Development, 2010; Steen 2003). Steen described the mathematics in the workplace as requiring a sophisticated use of elementary mathematics while in a classroom it is mostly an elementary use of sophisticated mathematics. South African education authorities, in trying to make a shift towards mathematics in real-life settings, introduced the school subject Mathematical Literacy which is compulsory for learners who are not studying Mathematics in Grades 10-12. Mathematical Literacy is described as follows in curriculum documents (DBE, 2011a):

The competencies developed through Mathematical Literacy allow individuals to make sense of, participate in and contribute to the twenty-first century world - a world characterised by numbers, numerically based arguments and data represented and misrepresented in a number of different ways. (p. 8)

The Mathematical Literacy curriculum includes topics such as inflation, taxation, tariff systems, health issues, household bills, exchange rates, maps and scale drawing, among many others (DBE, 2011a). Of interest to this study is the concept of inflation which has traditionally not been taught in a mathematics class, but is a context in which the elementary mathematics concept of percentage increase and decrease can be applied.

On its own, the percentage change procedure is used in the early grades by children as young as 11 years old (DBE, 2011b). However, when used to make interpretations about the consequences of the inflation rate figures, the procedure is no longer as simple. In this study, I try to unpack some of the complexities involved in applying the percentage change procedure to the context 
of inflation; I draw upon a framework used by Zazkis, Dautermann and Dubinsky (1996) to disentangle some of the contextual constraints. This is done to better understand how knowing in mathematics and knowing in the context of inflation develop together. The participants in the study were 406 practising Mathematical Literacy teachers who were enrolled in an in-service programme at a university in KwaZulu-Natal, South Africa. The research question underpinning this study is: What are the teachers' interpretations of the implicit contextual constraints when carrying out calculations based on the concept of inflation?

It is hoped that this study about teachers' use of the percentage change calculation in inflation can add to our knowledge about the conceptual understanding of mathematical literacy concepts. A further contribution is the use of theorems-in-action in the analysis which can provide valuable insight into teaching and learning. An improved understanding of the types of problems students could experience when faced with applying percentage changes successively, especially in the context of inflation, can help teachers plan how to mitigate these.

\section{Literature review}

A central concept underlying inflation calculations is that of percentage, on which there have been numerous studies. Parker and Leinhardt (1995), in their exhaustive review of seven decades of research into the concept of percentage, noted that the domain of percentage is covered in Grades 6 through 8. Consequently, most research about students' understanding of percentage has been carried out with young learners and has been concerned with how students perform, what specific errors students make and why students might make these errors' (Parker \& Leinhardt, 1995, p. 423). Parker and Leinhardt suggested that the richness of the percentage topic has been left unexplored because instructional emphasis has been placed on procedures. The concept of percentage forms part of the mathematical ideas encompassed by multiplicative structures (Vergnaud, 2009) and is encountered in financial mathematics concepts, proportional relationships, rates and exponential growth, among many others.

Percentage with its practical applications is widely used in the marketplace, in newspapers, in magazines, in the evening news, and in everyday commerce (Parker \& Leinhardt, 1995). Despite its apparent simplicity, there are many misconceptions and incorrect applications of the concept. People often make mistakes in evaluating the result of successive percentage changes, for example a reporter 'mistakenly judged a 5\% wage increase to be one-fourth, when it actually was one-fifth, of a preceding $20 \%$ decrease' in wages (Chen \& Rao, 2007, p. 327). There is often also confusion between the multiplicative meaning and an additive interpretation (Chen \& Rao, 2007; Parker \& Leinhardt, 1995) The concise, abstract language of percentages often uses misleading additive terminology with a multiplicative meaning. A change in the monthly inflation rate from $5 \%$ to $4 \%$ could be reported statistically as a decrease of one percentage point in the rate (using percentages as additive numbers) or as a $20 \%$ decrease in inflation (one point on five points using percentages as referent quantities to create a new percentage). Because of the dominance of operations with whole numbers, people may mistakenly apply a whole number strategy and add or subtract the individual percentages directly (Chen \& Rao, 2007).

Parker and Leinhardt (1995) note that by reporting data in percentage form it is possible to disguise or distort information about referent quantities (the original quantities on which the percentage was based). When data is reported in percentage form, information about the referent quantities may be easily distorted or misrepresented. When corporate executives receive a $5 \%$ salary increase, it may sound insignificant until the person's salary is revealed as R32 million. On the other hand, a 200\% percent increase in a domestic worker's wage may seem very large even though it may mean that the wage has increased from R1000 to R3000.

Studies about inflation have emanated mainly from economic perspectives focusing on people's everyday meaning and perceptions of inflation (Leiser \& Drori, 2005), inflation credibility (degree of acceptance of official inflation figures; Rossouw \& Padayachee, 2007), prediction and memory of rates of inflation (Kemp, 1991) and the psychology of inflation (Batchelor, 1986). In their study among economics students at a South African university Rossouw and Joubert (2005) found a higher degree of acceptance of the Consumer Price Index as an accurate indication of inflation than other indices. Rossouw and Padayachee (2007) found a great difference in inflation credibility among students in different faculties. The study found that students who studied in the economics field displayed the highest credibility, confirming that knowledge and information enhance the credibility of inflation figures. The authors argued that dissemination of information improves the understanding of inflation. One of their recommendations was that policy initiatives must be supported by means of communication strategies aimed at improving the general level of understanding of inflation and its measurement (Rossouw \& Padayachee, 2007). An important issue that needs to be explored is the extent to which ordinary people understand the inflation figures released each month by Stats SA. It is even more crucial that Mathematical Literacy teachers who teach the concept of inflation develop a deep understanding of the mathematical calculation behind the inflation rate figures reported in the press, to ensure that they can facilitate a sound understanding of the concept of inflation with their Mathematical Literacy learners.

In South Africa there are various inflation indices such as the Consumer Price Index, the Consumer Price Index excluding mortgage and the Producer Price Index. In this study the focus was on the Consumer Price Index which is taken as the average (weighted mean) cost of the 'shopping basket' of goods and services for a typical South African household. The typical South African basket contains about 1500 different consumer goods and services, and is based on many processes before 
average cost of the 'basket' is worked out. Price movements on the goods in the basket are measured and the Consumer Price Index is compiled using the price movements per product and their relative weight in the basket (Lehohla, 2011).

\section{Framework}

In order to better understand the linking of the mathematics and contextual perspectives, I draw upon a framework used by Zazkis et al. (1996) that they used to describe the merging of the visual and analytic perspectives when faced with a problem.

The visualisation/analysis model of Zazkis et al. (1996) specified the two elements - visualisation and analysis - as two interacting modes of thought. The authors have tried to disentangle acts of analysis and visualisation to represent how the two interacting perspectives of the object may move together until they form a new totality. Initially each act in a particular mode is separate. For example, the thinking may begin with an act of visualisation, $\mathrm{V}_{1}$, which could entail the learner looking at some 'picture' and constructing some mental actions or processes on it. The next step is an act of analysis, $\mathrm{A}_{1}$ ' which consists of some kind of coordination of the objects and processes constructed in step $\mathrm{V}_{1}$. As the movement between the $\mathrm{V}$ and $\mathrm{A}$ is repeated, the perspectives move closer together creating a spiral effect as illustrated in Figure 1.

As the movement between the two modes proceeds, the analytic and visual perspectives move closer together and at some stage become inseparable, with each one supporting the other and together forming a totality. In this study, we can distinguish two domains, the mathematical and the contextual settings. An understanding of the inflation rate figures requires continuous transitions between the mathematical and contextual settings. These shifts result in a series of re-interpretations of the mathematics signifiers, which are directed by the constraints of the contextual setting.

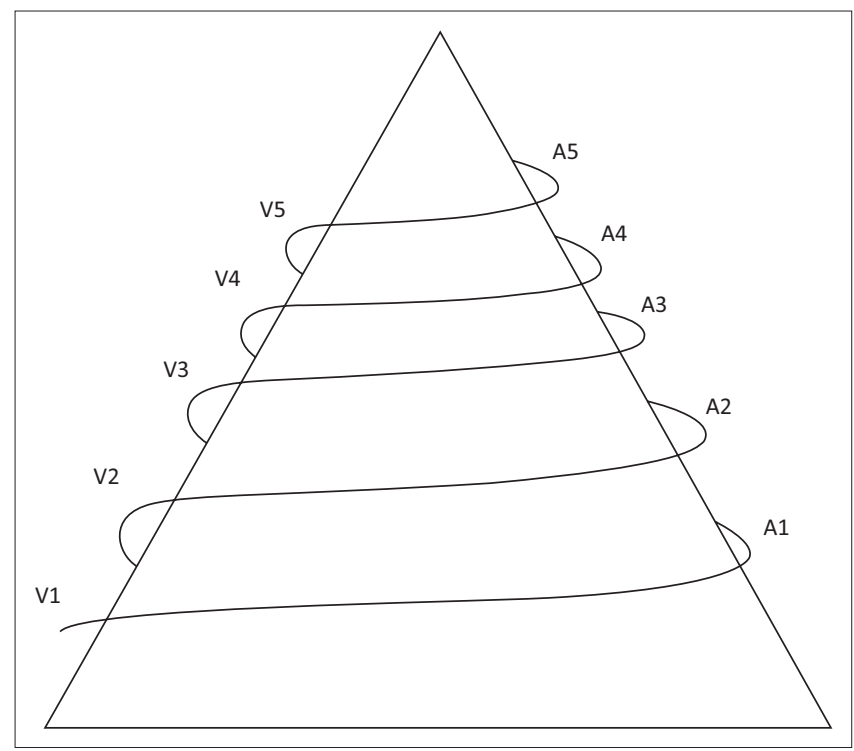

Source: Zazkis, R., Dautermann, J., \& Dubinsky, E. (1996). Coordinating visual and analytical strategies. A study of students' understanding of permutation and symmetry groups. Journal for Research in Mathematics Education, 27(4), 435-457. https://doi.org/10.2307/749876

FIGURE 1: The visualisation/analysis model.
The signifiers (or variables) in this setting are elaborated in Equations 1 to 4 and Tables 1 to 3 . These transitions can be viewed as similar to the movement between the two perspectives encompassed in the visualisation/analysis model. In this instance, as in the visualisation/analysis model, the reflection on the mathematics quantities deepens the reflection on the contextual quantities and vice versa and the movements between the two become progressively closer. At first the passage from one to the other may represent a major mental effort, but gradually, the two kinds of thought become more interrelated, fusing and forming a new totality.

What follows now is an attempt to disentangle the substance of the shifts between the two perspectives by examining the transformation of the arithmetic procedure used to find the percentage by which a quantity has changed into one that is used to quantify the percentage change in the cost of a basket of goods over a certain period. The basic procedure that measures the percentage change of a quantity is given in Equation 1, where $p_{0}$ is the initial value, $p_{1}$ is the final value and $C$ is the percentage change in the quantity expressed as a decimal.

$C=\frac{\text { difference between } p_{1} \text { and } p_{0}}{p_{0}}$

[Eqn 1]

This can be extended to capture the percentage change in costs of goods and services over a fixed period of 1 year. The inflation rate calculation process is represented as follows:

$i_{1}=$ inflation rate $=\frac{p_{1}-p_{0}}{p_{0}}$

Here, $p_{1}$ represents the current average price level, $p_{0}$ the price level a year ago, and the rate of inflation $\left(i_{1}\right)$ during the past year is calculated by Equation 2, where the symbol $i_{1}$ is used in place of $C$.

This relationship between the average price levels and the calculated value of the inflation rate gives meaning to the figures reported in the media each month as the 'monthly inflation rate' figures for the Consumer Price Index (Bansilal, 2011). Usually, inflation rate figures are reported on a monthly basis. The 'monthly inflation rate' refers to the year-on-year rate calculated on a monthly basis and does not represent a month-on-month rate. For example, if $i_{1}$ is the monthly inflation rate for March 2013, this means that $p_{0}$ and $p_{1}$ represent the price levels in March 2012 and March 2013 respectively.

When calculating the inflation rate, the various signifiers take on further contextual constraints that are elaborated in Box 1. It can be seen that Equation 2 has been constrained by conditions taken on by the signifiers (variables), which relate to the relationship between the variables, as detailed in Box 1 .

Box 1 captures the transition of $C$ (percentage change in a quantity) as described by Equation 1 in the mathematics domain to $i_{1}$ as described by Equation 2 embodied in the context of inflation.

For the purposes of this discussion, in order to understand the additional contextual constraint, Equation 2 is now 
BOX 1: Equation 2, showing the calculation of the inflation rate.

\begin{tabular}{|c|c|c|}
\hline$i_{1}=\frac{p_{1}-p_{0}}{p_{0}}$ & [Eqn 2] & $i_{1}$ is the current inflation rate \\
\hline Or equivalently: & & $p_{0}$ is the cost of the basket in the previous measurement \\
\hline$p_{1}=p_{0}+\left(i_{1} \times p_{0}\right)$ & & $p_{1}$ is the cost of the basket in the current measurement \\
\hline
\end{tabular}

The signifiers in Equation 1 have been further constrained when compared to those of Equation 2 . The times of measurement are now stipulated with $p$ being the initial and $p_{1}$ being the second measurement, hence the order of the difference calculation in the numerator is fixed.

BOX 2: Equation 3, showing the constraint made by the year.

\begin{tabular}{|c|c|c|}
\hline$i_{k}=$ inflation rate $=\frac{p_{k}-p_{k-1}}{p_{k-1}}$ & [Eqn 3] & $\begin{array}{l}i_{k} \text { is the inflation rate in the year } k \\
p_{k-1} \text { is the cost of the basket year } k-1\end{array}$ \\
\hline $\begin{array}{l}\text { Or equivalently: } \\
p=p+(i \times p-)\end{array}$ & & $p_{k}$ is the cost of the basket in year $k$ \\
\hline
\end{tabular}

Equation 3 now includes the additional condition of the year of measurement of the quantities.

BOX 3: Equation 4, showing the constraint of the month of measurement.

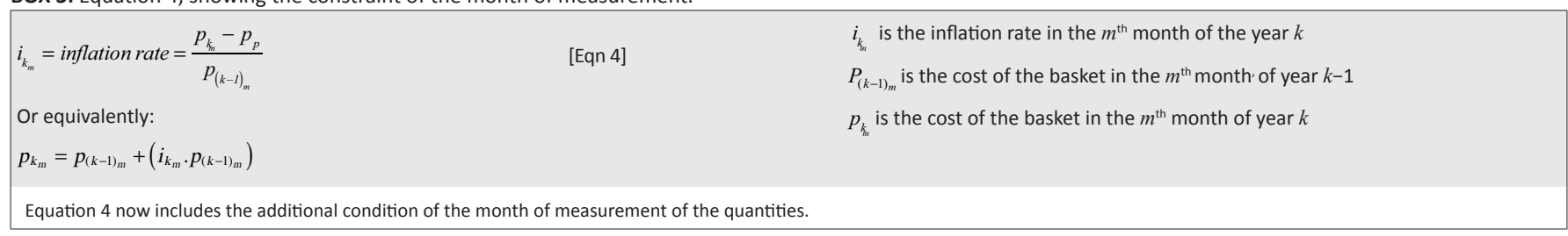

re-written to include the year, $k$, over which the measurement is made, and this is shown in Box 2.

Furthermore, there are 12 measurements, done on a monthly basis. Thus if $m$ is the month in which the measurement was made, $i_{k}$ can then be expressed as $i_{k_{m^{\prime}}}$ where $m=1,2,3,4, \ldots 12$. Hence, Equation 3 can be expressed even more generally as shown in Box 3.

Each contextual constraint, as in the visualisation/analysis model of Zazkis et al. (1996) requires a synthesis or coordination with the mathematical operations leading to progressively new interpretations of the signifiers and equation. Finally, the new object described by Equation 4 is encapsulated as an object (Bansilal, 2011).

\section{The study}

The participants in the study were a group of $406 \mathrm{KwaZulu-}$ Natal in-service Mathematical Literacy teachers who were enrolled in a programme designed to retrain practising teachers in the school subject Mathematical Literacy. The 2-year part-time programme comprised modules that focused on applications in different fields of mathematics. Inflation was one of the many concepts that were covered and the unit on inflation was covered over two 2-h sessions. During this time the teachers were introduced to the concept and they discussed ways in which the concept of inflation appeared and was used in everyday situations. The teachers also spent time in groups working with calculations based on inflation figures.

Data for this qualitative study were generated from the teachers' responses to items set as part of an assessment in the programme. The research question explored in the study was: What are the teachers' interpretations of the implicit contextual constraints when carrying out calculations based on the concept of inflation?
The main task presented a hypothetical item whose price was tracked over a particular period of 3 years by assuming that the price increases of the item were in line with the inflation rate figures at that time. During the particular period chosen, the inflation rate figures fluctuated with no steady pattern, and were presented in a graph. Figure 2 contains the task (question) and an accepted solution.

Note that the figures for the monthly inflation rates were provided in a graph containing all the monthly figures over a period of 4 years. Differences in reading of the values of the points on the graph were taken into consideration during the analysis process.

The analysis procedures were guided by the notion of 'theorems-in-action', which Vergnaud (1998) used in the context of the multiplicative conceptual field to describe the mathematical relations considered by students when they choose a concept to solve the given problem. These theorems are implicitly held by students and may not be articulated and may be correct or incorrect. During the analysis, each written response was first expressed as an equation or 'theorem-in-action' based on the various signifiers $\left(i_{k^{\prime}} p_{k}\right)$ and the operations carried out on them. The next layer of analysis involved grouping the various equations into a smaller number of categories according to the contextual constraints that were recognised or not recognised by the theorem-in action underpinning the response of each of the 406 teachers. An important reliability check when conducting qualitative research is to ensure traceability so that anyone can retrace the process. Cohen, Manion and Morrison (2011, p. 202) note that an audit trail 'enables the research to address the issue of confirmability of results'. The transcriptions of each of the teachers' responses were recorded in an Excel worksheet. Each response was translated into the underlying theoremin-action and recorded on the same sheet. The next stage involved the coding of these theorems-in-action. The coding 
Consider the following graph which shows the monthly inflation rates over the period January 2002 to December 2005 . Study the graph and answer the questions that follow.

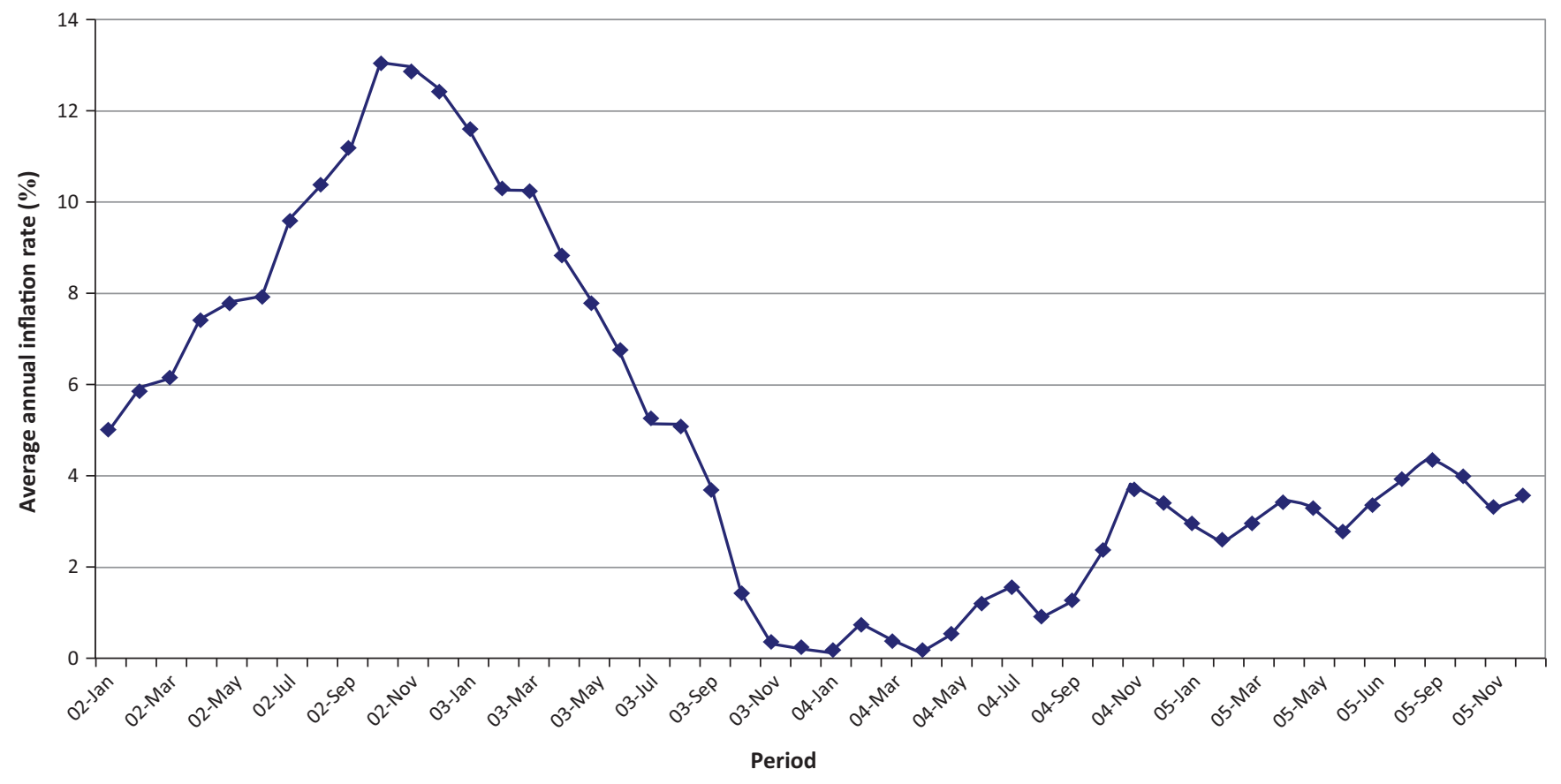

\begin{tabular}{|c|c|}
\hline Question & Accepted solution \\
\hline $\begin{array}{l}\text { In March } 2003, \text { my new car cost R55 } 000 . \\
\text { What would I have expected to pay for a } \\
\text { new car of the same make in March } 2005 \\
\text { if increases were in line with inflation? }\end{array}$ & 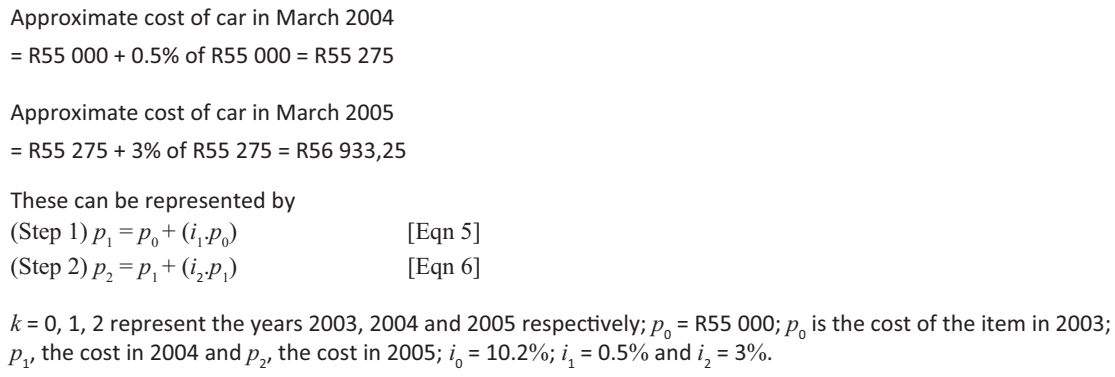 \\
\hline
\end{tabular}

FIGURE 2: Task with suggested solution.

was revisited by the author at a later stage to check for consistency and accuracy.

\section{Findings}

In this section, the teachers' calculations are presented in eight different categories which are then used to analyse the contextual conditions recognised by the teachers. Note that in representing the responses of teachers as examples of particular categories, the representations are reproduced verbatim. The responses are then presented in the form of an equation representing the theorem-in-action. Responses were coded according to the order in which the teachers appeared in a list. The code T26, for example, shows that it is the response of teacher number 26 .

\section{Category 1: Responses aligned to equation}

Of the 406 teachers, 133 produced calculations similar to that appearing in Figure 1 and a further 13 teachers made slight calculation errors. Hence, $35 \%$ of the group were able to present a calculation based on Equation 5 followed by Equation 6 .

\section{Category 2: Responses containing a one-step calculation using the inflation rate $\boldsymbol{i}_{2}$}

A large number of teachers (108) did a one-step calculation using a different version of Equation 6 that used the inflation rate $i_{2}$, instead of the rate $i_{1}$. An example of such a response (T29) is reproduced in Table 1.

Hence, $27 \%$ of the teachers produced a response that can be represented by Equation 7 . The inflation rate used was that for March $2005\left(i_{2}\right)$. Here $i_{2}$ was taken as the percentage by which $p_{0}$ (price of item in year 2003) increased 2 years later to $p_{2}$ (price of item in year 2005), displaying a misconception that the rate $i_{2}$ measures the percentage change in the price of goods over 2 years, that is $i_{2}=\frac{p_{2}-p_{0}}{p_{0}}$ instead of $i_{1}=\frac{p_{1}-p_{0}}{p_{0}}$ (Equation 2). 
TABLE 1: Response showing a one-step solution.

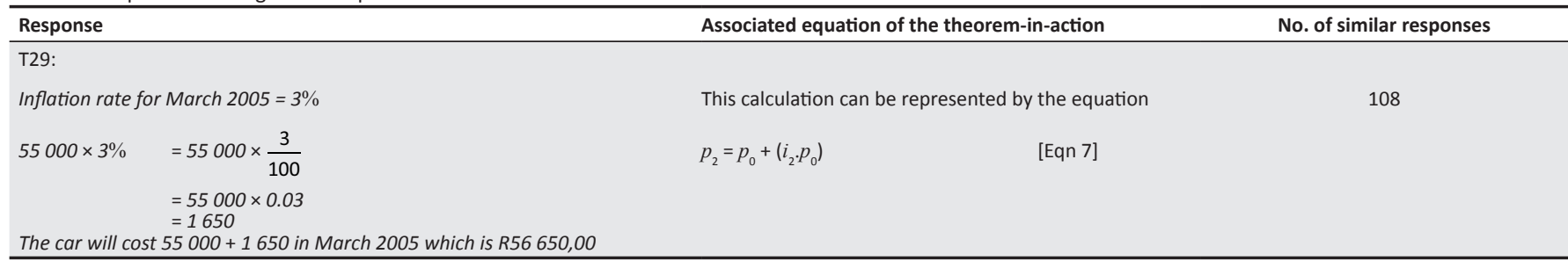

TABLE 2: Response of T18.

\begin{tabular}{|c|c|c|c|}
\hline Response & Associated equation & & No. of similar responses \\
\hline T18: & & & \\
\hline Cost $=55000\left(1+\frac{3}{100}\right)^{2}$ & $p_{2}+p_{0}\left(1+i_{2}\right)^{2}$ & [Eqn 8] & 9 \\
\hline
\end{tabular}

TABLE 3: Response of T35.

\begin{tabular}{|c|c|c|c|}
\hline Response & Associated equation & & No. of similar responses \\
\hline \multicolumn{4}{|l|}{ T35: } \\
\hline $\begin{array}{l}\text { March } 2003 \\
=R 55000+R 55000 \times 10.2 \% \\
=R 60610\end{array}$ & $p_{1}=p_{0}+\left(i_{0} \cdot p_{0}\right)$ & [Eqn 9] & 12 \\
\hline $\begin{array}{l}\text { March } 2005 \\
=R 55000+R 55000 \times 3 \% \\
=R 56650\end{array}$ & $p_{2}=p_{0}+\left(i_{2} \cdot p_{0}\right)$ & [Eqn 7] & \\
\hline
\end{tabular}

\section{Category 3: Use of the compound interest formula}

Some teachers (nine) used a similar approach to those in Category 2 but the calculation took into account the 2-year period between 2003 and 2005, and assumed that the inflation rate was constant over the 2-year period. These teachers used the compound interest formula to calculate the cost. T18's response is reflected in Table 2 .

In this approach, the annual inflation rate has been assumed to be the same over the 2-year period of calculation. These teachers used a compounding formula, which is sometimes used in illustrative predictions when the rate is averaged over a few years. However, in this calculation the assumption is that the inflation rate was constant for both years.

\section{Category 4: Responses containing two separate calculations}

Another approach, based on yet a different combination of Equation 5 and Equation 6 was presented by 12 teachers. These teachers produced a response consisting of two separate calculations, the first one using the March 2003 inflation rate $\left(i_{0}\right)$, and the second disconnected calculation being the same as that produced by the people in Category 1 using Equation 7. One such response by T35 is reflected in Table 3.

As is seen, from the theorem-in-action, there is no connection between the two calculations and the answers are presented as two separate results. These 12 teachers' responses do not show recognition of the recursive nature of the price calculation, namely that the changes in the price of the item over consecutive measurement periods are cumulative with the subsequent inflation rate one acting on the changed price. Equation 9 takes $i_{0}$ as the percentage change of $p_{0}$ to $p_{1}$, instead of it being $i_{1}$. Equation 7 was also identified in Category 2, and reflects a misconception that the rate $i_{2}$ measures the percentage change in the price of goods over 2 years, from $p_{0}$ to $p_{2}$.

\section{Category 5: Use of the inflation rate $\boldsymbol{i}_{0}$}

A similar theorem-in-action to those of Category 4 was evident in the responses of 21 teachers who also produced a response of the form Equation 10, with some producing a one-step calculation based on Equation 9 and others using a two-step or even three-step calculation using Equation 9 in the first step. Table 4 summarises the various responses of these 21 teachers.

Table 4 shows variations in the ways in which Equation 9 was used, with 11 teachers producing a one-step calculation (only Equation 9) while a further five did a two-step calculation (Equation 9 followed by Equation 10). Five teachers produced a three-step solution using the three inflation rates $i_{0^{\prime}} i_{1}$ and $i_{2^{\prime}}$ incorrectly assuming that there are three possible year-onyear inflation rate calculations over a 2-year period.

\section{Category 6: Use of other rates}

There were five teachers who produced a one-step calculation using a rate different from $i_{0}, i_{1}$ or $i_{2}$. One of these teachers used the VAT (Value Added Tax) rate (Table 5).

\section{Category 7: Calculations assuming a decrease in price}

Many teachers (68) felt strongly that the car would be cheaper in 2005 than it was in 2003, and their theorems-in-action encompassed a percentage decrease operation on $p_{0}$ as shown in Table 6. In fact, 29 teachers used a percentage decrease calculation, that is, a subtraction form of Equation 7, while others used different variations of the percentage decrease calculation. 
TABLE 4: Responses that used the inflation rate $i_{0}$

\begin{tabular}{|c|c|c|c|}
\hline Response & Associated equation & & No. of similar responses \\
\hline \multicolumn{4}{|l|}{ T23: } \\
\hline $\begin{array}{l}2003-10 / 100 \\
=10 / 100 \times 55000 \\
=5500+55000 \\
=60500,00\end{array}$ & $p_{1}=p_{0}+\left(i_{0} \cdot p_{0}\right)$ & [Eqn 9] & 11 \\
\hline \multicolumn{4}{|l|}{ T248: } \\
\hline $\begin{array}{l}2004=(10.2 \% \text { of } 55000)+55000 \\
=5610+55000 \\
R 60610 \text { (in the beginning of 2005) }\end{array}$ & $p_{1}=p_{0}+\left(i_{0} \cdot p_{0}\right)$ & [Eqn 9] & 5 \\
\hline $\begin{array}{l}2005=(0.5 \% \text { of } 60610)+60610 \\
=303,05+60610 \\
=R 60913,05\end{array}$ & $p_{2}=p_{1}+\left(i_{1} \cdot p_{1}\right)$ & [Eqn 10] & \\
\hline \multicolumn{4}{|l|}{ T42: } \\
\hline $\begin{array}{l}\text { March } 2003 \\
55000+10,2 \times 55000=60610\end{array}$ & $p_{1}=p_{0}+\left(i_{0} \cdot p_{0}\right)$ & [Eqn 9] & 2 \\
\hline $\begin{array}{l}\text { March } 2004-60610+0,3 \% \times 60610 \\
=62428,3\end{array}$ & $p_{2}=p_{1}+\left(i_{1} \cdot p_{1}\right)$ & [Eqn 10] & \\
\hline $\begin{array}{l}\text { March } 2005=62428,3+3 \% \times 6242 \\
=64301,15\end{array}$ & $p_{3}=p_{2}+\left(i_{2} \cdot p_{2}\right)$ & [Eqn 11] & \\
\hline \multicolumn{4}{|l|}{ T88: } \\
\hline $\begin{array}{l}\text { March } 2003-10.2 \% \\
R 55000 \times 10.2 \% \\
R 55000 \times 0,102 \\
R 5610 \\
R 55000+R 5610=60610\end{array}$ & $p_{1}=p_{0}+\left(i_{0} \cdot p_{0}\right)$ & [Eqn 9] & 3 \\
\hline $\begin{array}{l}\text { March } 2004-0.2 \% \\
R 60610+(55000 \times 0.2 \% \\
R 60610+R 110=60720\end{array}$ & $p_{2}=p_{1}+\left(i_{1} \cdot p_{0}\right)$ & [Eqn 12] & \\
\hline $\begin{array}{l}\text { March } 2005-3 \%-0.03 \\
R 60610+(55000 \times 0.03) \\
R 60610+1650 \\
=R 62260\end{array}$ & $p_{3}=p_{2}+\left(i_{2} \cdot p_{0}\right)$ & [Eqn 13] & \\
\hline
\end{tabular}

TABLE 5: Response illustrating other rates.

\begin{tabular}{lll}
\hline Response & Associated equation & \\
\hline T56: & & \\
New car cost $R 55000+$ VAT & $p_{1}=p_{0}+\left(i_{3} \cdot p_{0}\right)$ & \\
$R 55000+14 \% / 100$ & & \\
$R 55000+7700$ & & \\
$R 62700$ & & \\
\hline
\end{tabular}

There was a large number (19) who first found the difference between $i_{0}$ and $i_{2}$ and used the result in the percentage decrease calculation denoted as Equation 21. The teachers' responses in this group contradicted the order of the difference calculation in Equation 2, because the sign of the inflation rates in their calculation is negative. So Equation 18 from Table 6 for example, can be expressed as $i_{1}=\frac{p_{0}-p_{1}}{p_{0}}$, showing that the order condition discussed in Box 2 of the framework has been contradicted. The responses that assumed a decrease in price are presented in Table 6.

Hence the responses of 68 teachers revealed that they believed so strongly that the price should have decreased over that period, that they disregarded the constraint of the order of the difference in the calculation.

\section{Category 8: Other responses}

Responses that could not be identified with the seven preceding categories were placed in the Category 'Other responses' and these are described in this section. Table 7 presents two equations and the others are described thereafter.
There were three teachers who took the inflation rate as a month-on-month rate, as shown by T405 in Table 7. Some responses were based on a direct proportion calculation (five people) that set up various incorrect proportions as shown by T4 in Table 7.

There were 11 teachers whose responses did not specify details of the calculations, and 18 teachers who did not produce any response.

\section{Discussion}

The findings indicate that all except 34 teachers included a percentage increase or decrease calculation showing that $92 \%$ of the group did not have problems with using the percentage change formulas represented by the decontextualised formula of Equation 1. However, it was in identifying the quantities anchored in the context, and interpreting the realisations of contextual constraints, that most difficulties emerged. The representation of each teacher's response in terms of a theorem-in-action enabled the identification of the conditions that were not recognised by each teacher. 
TABLE 6: Responses which assumed a decrease in price.

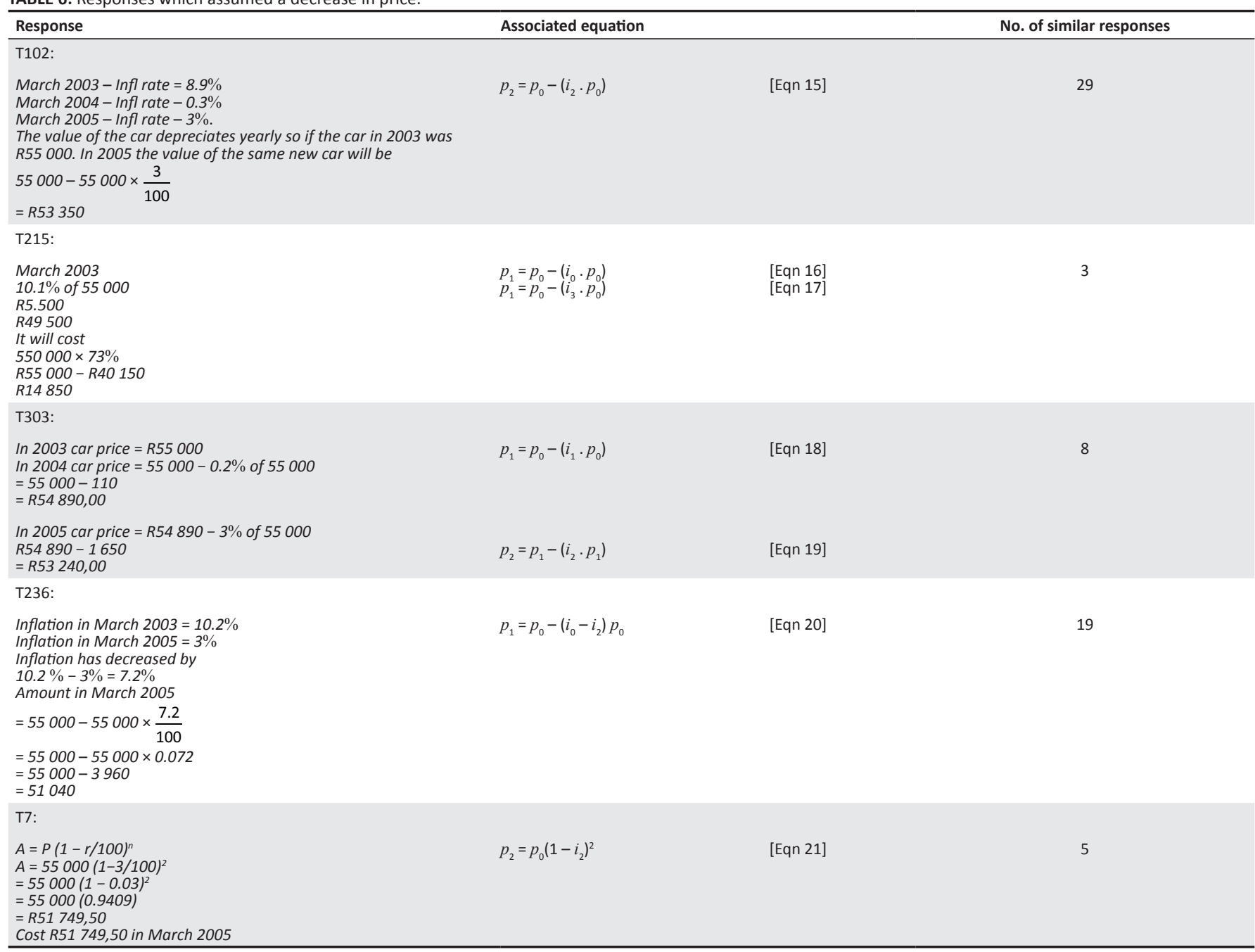

TABLE 7: Responses taken as 'other'.

\begin{tabular}{|c|c|c|c|}
\hline Response & Associated equation & & No. of similar responses \\
\hline \multicolumn{4}{|l|}{ T405: } \\
\hline $\begin{array}{l}R 55000 \times 3 \% / 100 \\
R 1650 \times 24 \text { Months } \\
R 39600+R 55000 \\
R 94600\end{array}$ & $p_{1}=p_{0}+24\left(i_{2} p_{0}\right)$ & [Eqn 22] & 3 \\
\hline \multicolumn{4}{|l|}{ T4: } \\
\hline $\begin{array}{l}\frac{10.5}{100}=R 55000 \\
\frac{3}{1}=x\end{array}$ & $p_{1}=\left(\frac{p_{0}}{i_{0}}\right) \cdot i_{2}$ & [Eqn 23] & 5 \\
\hline $\begin{array}{l}100 \\
0,105 x=1650 \\
x=R 15714,29\end{array}$ & & & \\
\hline
\end{tabular}

As explained in the framework, the simplistic inflation rate calculation is given by Equation 2:

$i_{1}=\frac{p_{1}-p_{0}}{p_{0}}$

However, a more comprehensive representation of the relationship between the various contextual quantities is given by Equation 4:

$\left(i_{k_{m}}\right)=$ inflation rate $=\frac{p_{k_{m}}-p_{(k-1)_{m}}}{p_{(k-1)_{m}}}$

[Eqn 4]
The analysis revealed that the extent of the teachers' engagement in the problem varied widely. It was found that some contextual conditions were more easily grasped than others. The discussion is arranged around the various contextual constraints embedded in the inflation rate calculation process.

\section{Constraint of the base quantity}

One constraint was on the base quantity in calculating the percentage change. The initial base quantity of $p_{0}$ from 
Equation 2 has attained a realisation into $p_{k-1}$ as the base for the percentage change comparison as shown by:

$i_{k}=\frac{p_{k}-p_{k-1}}{p_{k-1}}$ or $p_{k}=p_{k-1}+\left(i_{k} \cdot p_{k-1}\right)$

Responses in Category 5 which were represented using Equation 12 and Equation 13 contradicted this condition of what the base or referent quantity should be in each percentage increase calculation. For example, in Equation 12, $p_{2}=p_{1}+\left(i_{1} \cdot p_{0}\right)$ or equivalently, $i_{1}=\frac{p_{2}-p_{1}}{p_{0}}$, which means taking the difference in the price from year 1 to year 2 as a percentage of year 0 . These teachers have not demonstrated an understanding of the meaning behind the inflation rate figures: that the inflation rate figure is the measure of the percentage by which the cost of the basket in the previous year has increased. Parker and Leinhardt (1995) noted that the presentation of data in percentage form sometimes makes it difficult for the referent quantities (the original quantities on which the percent was based) to be discerned. This can often lead to a distortion or misinterpretation of information, which may have been the situation here.

\section{Constraint of the year of measurement}

Closely related to the condition on the base or referent quantity in the calculation was the associated constraint of the year of measurement of the quantities, as described in Equation 3, which shows the relationship between quantities $i_{k^{\prime}}$ and $p_{k}$ and $p_{k-1}$, where $p_{k}$ is the result, but only when the operation of adding a percentage change is carried out on $p_{k-1}$ using $i_{k}$ as the rate. This struggle to recognise the constraining condition of the years on the variables $p_{k}$ and $i_{k}$ was evident in the responses shown in categories $2,4,5$ and 6 and exemplified in Equations 7, 9, 10, 11, 12, 13 and 14. The theorems-in-actions underpinning these equations do not correctly reflect the relationship that is described by Equation 3. In fact, non-recognition of this condition constituted the biggest hurdle in this task, with the responses of 162 teachers overlooking this constraint. The constraint of the year required a simultaneous consideration of two quantities, which constitutes areas of conceptual difficulty in other contexts such as distance, speed and velocity. It required reasoning about the relationship between the cost variables $p_{k}$ and $p_{k-1}$ and the inflation rate variable, $i_{k}$. In this case, there is a changing relationship between and within the variables $i_{k}$ and $p_{k}$ and it was necessary to recognise these different relationships. Tasar (2010) noted a similar difficulty (in the context of distance, speed and acceleration) in understanding the different ways of decrease or increase (e.g. as a constant rate of increase, increasing rate of increase, and a decreasing rate of increase). Tasar reflected that a fall in inflation rate is an example of a decreasing rate of increase, that is, the prices are increasing by a smaller percentage, contrary to the misunderstanding that it indicates a fall in prices. Unpacking these relationships requires what Oerhtman, Carlson and Thompson (2008) describe as covariational reasoning. This refers to the ability to form an image of two varying quantities and coordinating their changes in relation to each other, which seems to be difficult to achieve (Oerhtman et al., 2008; Thompson, 1994). For a more detailed discussion of this covariational relationship, the reader is referred to Bansilal (2017).

\section{Constraint on the order of the difference}

Another constraint on the procedure arises from the order of the calculation of the change in the quantity. The original difference between $p_{1}$ and $p_{0}$ in Equation 1 has attained a realisation into $p_{k}-p_{k-1}$, as shown in Equation 3, where the order is important, and the sign of the difference denotes specific meaning. This order of the difference constraint constituted a problem for many teachers whose responses were described in Category 7, and exemplified in Equations 15-21. The non-recognition of the constraint is related to the misconception that a decrease in the inflation rate should be associated with a decrease in prices. It is not surprising that many teachers worked with depreciation, since a typical scenario in dealing with car purchases is one that considers the value of the purchased vehicle after a certain time period. This involves depreciation, and this is often found in textbook tasks but, more importantly, affects teachers in their daily lives. It is possible that the teachers did not fully understand the context or pay enough attention to the question and assumed that the question asked for the value of the same car after 2 years.

These teachers went as far as subtracting the two rates and putting the difference as the net effect of inflation over the 2 years, to ensure that the cost 2 years later, was lower than the cost in the first year. In subtracting the two rates, the teachers have mistakenly applied a whole number strategy to the percentage values by subtracting the individual percentages directly, as if they were whole numbers (Chen \& Rao, 2007). A percentage actually is a comparison between two referent quantities, and cannot make sense unless one knows what the referent quantities are (Parker \& Leinhardt, 1995). The subtraction of two percentage values has no meaning because the referents in each case are different, and the result of the difference is thus not appropriate for this context of application. The referent quantities in any percentage relationship is very important and one cannot make any conclusion about the relationship without considering them because they are a fundamental property of percentage.

\section{Constraint of the recursive nature of the inflation calculation}

There were some responses which ignored the recursive nature of the calculations: that is, the cumulative effect of

1.A detailed discussion of the covariational reasoning with respect to the changes in the inflation rates and the changes in the prices of goods appears in Bansilal (2017). 
increasing (or decreasing!) prices to the cost of the basket. The rate $i_{k}$ is the percentage change in prices from year $k-1$ to year $k$ and $i_{(k+1)}$ is the percentage change in prices from year $k$ to year $k+1$. The variable $p_{k}$ can also be calculated as follows:

$p_{k}=p_{(k-1)}\left(1+i_{k}\right)=p_{(k-2)}\left(1+i_{k-1}\right)\left(1+i_{k}\right)$

Hence the cumulative effect of the successive percentage increases or decreases in the cost of the basket is factored into the signifier $p_{k}$. The neglect of this constraint was identified in Categories 4 and 8. The application of the percentage increases or decreases is not complicated (last year's price plus the increase caused by inflation). However, it is the recognition that the cumulative effect of inflation is enabled by the repeated application of the percentage change formula that seems to be the issue. Thompson (1994) alluded to the difficulty of recognising this recursive nature of the inflation calculation. He reported that when given a question based on a graph of yearly inflation figures, many mathematics secondary teachers looked at inflation as increase in price per year (i.e., rate of increase with respect to time), which translates into slope, instead of as percentage change, which is a recurrence relationship' (Thompson 1994, p. 21)

\section{Constraint of the month}

The condition of $m$, where $m$ represents the month for which the inflation rate is being reported, is shown in Equation 4. Thus, the quantities $i_{k,} p_{k}$ and $p_{(k-1)}$ attain a further realisation into $i_{k_{m}}, p_{k_{m}}$ and $p_{(k-1)_{m}}$ respectively, where $k$ is the year and $m$ is the month of measurement. The month was provided in the task, making it very difficult to ignore this condition; however, there were three people in Category 8 who misused the annual rate. They assumed it was a monthly rate by multiplying the monthly rate by 24 .

\section{Understanding the inflation rate}

The analysis via theorems-in-action identified a variety of ways in which the various quantities (or signifiers) were combined and the ways in which the relationships between the quantities were constructed. The number of different equations that were uncovered was at least 24, each of which revealed a different understanding of the relationship between the signifiers. The choice of combinations of the signifiers and the operations on them are likely to be arbitrary, such as T4, if the understanding of the relationships between the contextual quantities is unsound. Clearly it is difficult to represent a situation without a clear understanding of the context. The various ways of carrying out operations on the different quantities, demonstrate the teachers' struggles in trying to combine the mathematics and the contextual domains. The visualisation/analysis model, according to Zazkis et al. (1996) results ultimately in a refinement of the thinking strategies and a more sophisticated reflective analysis. In the case of the question in this research study the thinking strategy remains the same: last year's price + increase caused by inflation. The increased sophistication in the reflective analysis emerges in the recognition that the cumulative effect of inflation is enabled by the repeated application of the percentage change formula. The visual representation of the visualisation/analysis model with its developing spirals shows how the reflections can increase in sophistication and, as each constraint is recognised, it leads to the selection and appropriate interpretation of the relevant quantities.

\section{Conclusion}

In this article, the written responses of 406 Mathematical Literacy teachers were scrutinised to identify their interpretations of the contextual constraints involved in applying the percentage change procedure to the context of inflation. The study provided a specific and detailed analysis of the complexities that can arise in the use of rates and percentage for working with inflation. Of the 406 responses that were analysed, $65 \%$ of them were unable to take account of all the contextual constraints. Some of the constraints were more easily taken up than others. For example, most teachers realised that the month of measurement was constant, while most struggled with interpreting the role of the year, $k$, in the relationship between the quantities. The study illustrates the complex interaction between mathematics and context that arise when applying mathematical tools to concepts in other fields. The manner in which particular elements of the context of application expand and adapt the mathematical tool as it is interpreted, as well as the manner in which the use of the mathematical tool forces the precise identification of elements of the context are both important and evident in the data of this study. The understanding of the relationship between the contextual quantities shifts and is shifted by the understanding of the mathematical relationships. Developing our understanding of this interpretation process is useful for deepening the teaching and learning of the application of mathematics.

An implication of this study is that in order to deal with complex applications, one must have a sophisticated understanding of the mathematics procedures, even for a procedure as elementary as the percentage change calculation. This resonates with Steen's (2003) call for the development of sophisticated understanding of elementary mathematics rather than elementary understanding of sophisticated mathematics. This study has illustrated that one of the complexities related to attaining a sophisticated understanding of elementary mathematics is that of understanding the constraints of the context in which the elementary mathematics is being applied. The study has also raised issues about whether the in-service programme provided adequate support for the teachers to engage with the contextual settings. Most teachers did not develop a robust understanding of the notion of inflation, suggesting that the purpose and design of such programme must be carefully reconsidered. 


\section{Acknowledgements Competing interests}

The author declares that she has no financial or personal relationships that may have inappropriately influenced her in writing this article.

\section{References}

Bansilal, S. (2011). Unpacking Mathematical Literacy teachers' understanding of the concept of inflation. African Journal for Research in Mathematics, Science and Technology Education, 15(2), 179-190. https://doi.org/10.1080/10288457.2011. 10740711

Bansilal, S. (2017). Teachers' understanding of inflation: Developing a crystalline concept. International Journal of Mathematical Education in Science and Technology, 48(1), 83-93. https://doi.org/10.1080/0020739X.2016.1238517

Batchelor, R.A. (1986). The psychophysics of inflation. Journal of Economic Psychology, 7(3), 269-290. https://doi.org/10.1016/0167-4870(86)90021-8

Chen, H., \& Rao, A.R. (2007). When two plus two is not equal to four: Errors in processing multiple percentage changes. Journal of Consumer Research, 34, 327-339. https://doi.org/10.1086/518531

Cohen, L., Manion, L., \& Morrison, K. (2011). Research methods in education. London Routledge Falmer.

Cooper, B., \& Dunne, M. (2004). Constructing the 'legitimate' goal of a 'realistic' maths item: A comparison of 10-11 and 13-14 year olds. In B. Allen, \& S. Johnson-Wilde (Eds.), Mathematics education: Exploring the culture of learning (pp. 69-90) London: Routledge Falmer.

De Lange, J. (2003). Mathematics for literacy. In B. Madison, \& L. Steen (Eds.) Quantitative literacy: Why numeracy matters for schools and colleges (pp. 75-89). Princeton, NJ: National Council on Education and the Disciplines.

Department of Basic Education. (2011a). Curriculum and assessment policy statement Further Education and Training Phase. Grades 10-12. Mathematical Literacy. Pretoria: DBE.

Department of Basic Education. (2011b). Curriculum and assessment policy statement, Intermediate Phase. Grades 4-6. Mathematical Literacy. Pretoria: DBE.

Kemp, P. (1991). Remembering and dating past prices. Journal of Economic Psychology, 12, 431-445. https://doi.org/10.1016/0167-4870(91)90025-0

Lehohla, P. (2011, February 20). No room for wannabes in recording local figures. The Business Report, p. 3.

Leiser, D., \& Drori, S. (2005). Naïve understanding of inflation. Journal of SocioEconomics, 34, 179-198. https://doi.org/10.1016/j.socec.2004.09.006
Moschkovich, J.N. (2002). An introduction to examining everyday and academic mathematical practices. Journal for Research in Mathematics Education. Monograph (Vol. 11, pp. 1-11). Reston, VA: NCTM. http://dx.doi.org/10.2307/ Monog
749961

Oerhtman, M.C., Carlson, M.P., \& Thompson, P.W. (2008). Foundational reasoning abilities that promote coherence in students' understandings of function. In M.P. Carlson, \& C. Rasmussen (Eds.), Making the connection: Research and practice in undergraduate mathematics (pp. 27-42). Washington, DC: Mathematical in undergraduate mathematics (pp. 27-42). Washington, DC: Mathema
Association of America. https://doi.org/10.5948/UPO9780883859759.004

Organisation for Economic Co-operation and Development. (2010). Draft 2012 Pisa mathematics framework. Copenhagen: PISA.

Orrill, R. (2001). Mathematics, numeracy and democracy. In L.A. Steen (Ed.), Mathematics and democracy. The case for quantitative literacy (pp. xiii-xx). Princeton, NJ: The National Council on Education and the Disciplines. Available from http://www.maa.org/ql/mathanddemocracy.html

Parker, M., \& Leinhardt, G. (1995). Percent: A privileged proportion. Review of Educational Research, 65(4), 421-481. http://dx.doi.org/10.3102/0034654 3065004421

Rossouw, J., \& Joubert, F. (2005). A perspective on the measurement of inflation credibility. South African Journal of Economic and Management Science, 8(4) 499-506. http://dx.doi.org/10.4102/sajems.v8i4.1179

Rossouw, J., \& Padayachee, V. (2007). A study on inflation credibility among students at the University of Pretoria. South African Journal of Economic and Management Sciences, 10(1), 145-154. http://dx.doi.org/10.4102/sajems.v10i1.543

Steen, L.A. (2003). Data, shapes, symbols: Achieving balance in school mathematics. In B. Madison, \& L.A. Steen (Eds.), Quantitative literacy: Why numeracy matters for schools and colleges (pp. 53-74). Princeton, NJ: National Council on Education and the Disciplines. Available from http://www.maa.org/sites/default/files/pdf/ QL/WhyNumeracyMatters.pdf

Tasar, M.F. (2010). What part of the concept of acceleration is difficult to understand The mathematics, the physics, or both? ZDM: The International Journal on Mathematics Education, 42(5), 469-482. https://doi.org/10.1007/s11858-0100262-9

Thompson, P.W. (1994). Students, functions, and the undergraduate curriculum. In E. Dubinsky, A.H. Schoenfeld, J.J. Kaput, \& T.P Dick (Eds.), Research in collegiate mathematics education (Vol. 1, pp. 21-44). Providence, RI: American Mathematical Society. http://dx.doi.org/10.1090/cbmath/004

Vergnaud, G. (1998). A comprehensive theory of representation for mathematics education. Journal of Mathematical Behavior, 17(2), 167-181. https://doi.org/ 10.1016/S0364-0213(99)80057-3

Vergnaud, G. (2009). The theory of conceptual fields. Human Development, 52(2), 83-94. https://doi.org/10.1159/000202727

Zazkis, R., Dautermann, J. \& Dubinsky, E. (1996). Coordinating visual and analytical strategies. A study of students' understanding of permutation and symmetry groups. Journal for Research in Mathematics Education, 27(4), 435-457. https:// doi.org/10.2307/749876 